\title{
QUEEN'S
QNEIVERSITY
BELFAST
}

\section{The influence of Notches on Domain Dynamics in Ferroelectric Nanowires}

McMillen, M., McQuaid, R., Haire, S. C., McLaughlin, D., Chang, L-W., Schilling, A., \& Gregg, M. (2010). The influence of Notches on Domain Dynamics in Ferroelectric Nanowires. Applied Physics Letters, 96(4), [042904]. https://doi.org/10.1063/1.3300638

Published in:

Applied Physics Letters

Document Version:

Peer reviewed version

Queen's University Belfast - Research Portal:

Link to publication record in Queen's University Belfast Research Portal

Publisher rights

(C) 2010 American Institute of Physics.

This work is made available online in accordance with the publisher's policies. Please refer to any applicable terms of use of the publisher.

\section{General rights}

Copyright for the publications made accessible via the Queen's University Belfast Research Portal is retained by the author(s) and / or other copyright owners and it is a condition of accessing these publications that users recognise and abide by the legal requirements associated with these rights.

Take down policy

The Research Portal is Queen's institutional repository that provides access to Queen's research output. Every effort has been made to ensure that content in the Research Portal does not infringe any person's rights, or applicable UK laws. If you discover content in the Research Portal that you believe breaches copyright or violates any law, please contact openaccess@qub.ac.uk. 


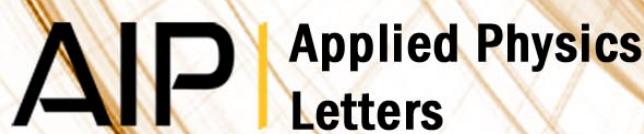

The influence of notches on domain dynamics in ferroelectric nanowires

M. McMillen, R. G. P. McQuaid, S. C. Haire, C. D. McLaughlin, L. W. Chang et al.

Citation: Appl. Phys. Lett. 96, 042904 (2010); doi: 10.1063/1.3300638

View online: http://dx.doi.org/10.1063/1.3300638

View Table of Contents: http://apl.aip.org/resource/1/APPLAB/v96/i4

Published by the American Institute of Physics.

Additional information on Appl. Phys. Lett.

Journal Homepage: http://apl.aip.org/

Journal Information: http://apl.aip.org/about/about_the_journal

Top downloads: http://apl.aip.org/features/most_downloaded

Information for Authors: http://apl.aip.org/authors

\section{ADVERTISEMENT}

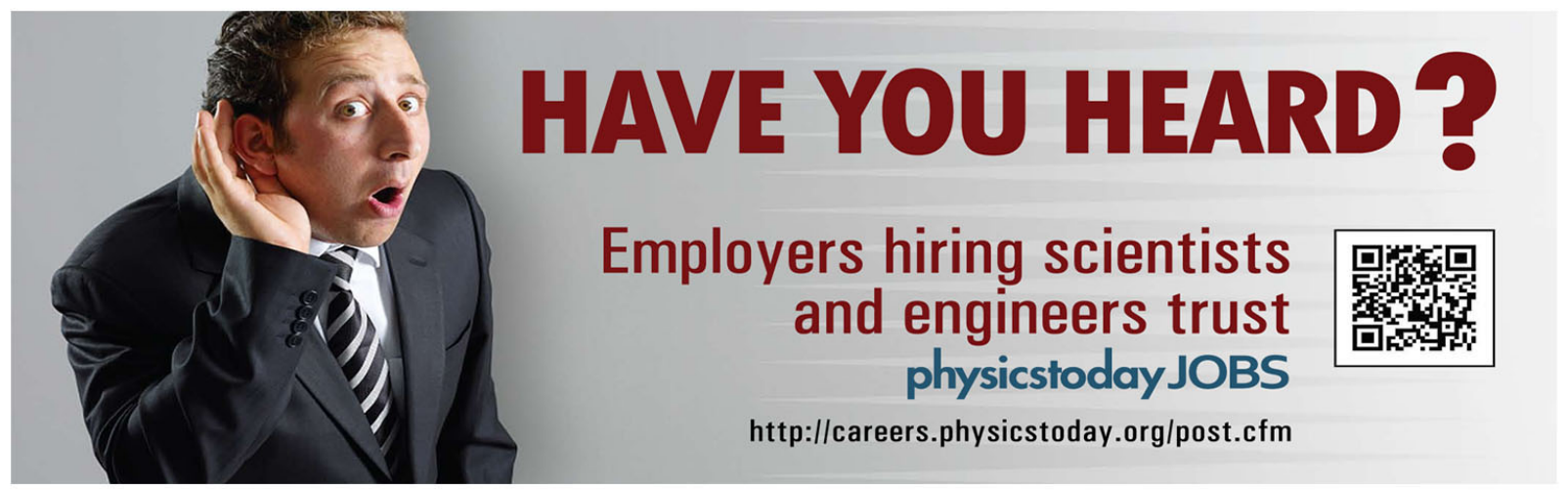




\title{
The influence of notches on domain dynamics in ferroelectric nanowires
}

\author{
M. McMillen, R. G. P. McQuaid, S. C. Haire, C. D. McLaughlin, L. W. Chang, A. Schilling, \\ and J. M. Gregg ${ }^{\text {a) }}$ \\ Department of Pure and Applied Physics, Centre for Nanostructured Media, School of Maths and Physics, \\ Queen's University Belfast, Belfast BT7 1NN, United Kingdom
}

(Received 26 November 2009; accepted 16 December 2009; published online 29 January 2010)

\begin{abstract}
The extent to which notches inhibit axial switching of polarization in ferroelectric nanowires was investigated by monitoring the switching behavior of single crystal $\mathrm{BaTiO}_{3}$ wires before and after patterning triangular notches along their lengths. Static zero-field domain patterns suggested a strong domain-notch interaction, implying that notches should act as pinning sites for domain wall propagation. Surprisingly though, notches appeared to assist, rather than inhibit, polar switching. The origin of this effect was rationalized using finite element modeling of the electric field distribution along the notched wire; it was found that the air gap associated with the notch acted to enhance the local field, both in the air, and in the adjacent region of the ferroelectric. It seems that this local field enhancement outweighs any pinning interactions. (c) 2010 American Institute of Physics. [doi:10.1063/1.3300638]
\end{abstract}

There is a great disparity in the extent to which the behavior of ferromagnetic and ferroelectric domains have been mapped and understood in nanoscale structures and devices. For example, in mesoscale disks and nanoscale rings of soft ferromagnetic materials, it has been known for some time that demagnetizing fields cause the formation of vortex domain states. ${ }^{1-7}$ Not only have these magnetic vortices been imaged, ${ }^{1-5}$ but the dynamic modes of vortex switching have also been examined. ${ }^{5-7}$ By contrast, in ferroelectrics, while atomistic simulations have suggested that analogous polarization vortices should exist, ${ }^{8-11}$ only circumstantial evidence for their presence has ever been found. ${ }^{12-15}$

Of particular relevance to the work presented herein, is the extent to which interactions between domain walls and perturbations in surface morphology are understood within the two ferroic subgroups. In magnetics research, as part of the development of "race-track" memory, Parkin and co-workers ${ }^{16-19}$ have pioneered an understanding of the pinning potentials associated with notches and a variety of domain wall types. Physics relating to controlled domain wall migration, from notch to notch, has been developed; in addition, elegant concepts such as "resonant amplification," where current pulses cause domain walls to resonate within their pinning potential wells, have not only been conceived of, but also experimentally realized. ${ }^{18,19}$ In ferroelectrics, however, relatively little has been done to explore the behavior of domains in nanowires ${ }^{20-28}$ and the nature of the interactions between domains and local variations in nanowire morphology is almost totally unexplored. ${ }^{28}$ While ferroelectric race-tracks are not of technological interest, basic mapping of the manner in which domain walls migrate in small scale ferroelectric objects is highly important; switching of smaller and more morphologically complex capacitors, planned for future ferroelectric random access memory chips, ${ }^{29}$ relies critically on domain wall propagation.

In this letter, the influence that notches have on the behavior of ferroelectric domains has been studied in single

${ }^{a)}$ Electronic mail: m.gregg@qub.ac.uk. crystal wires of $\mathrm{BaTiO}_{3}$. While static domain patterns suggested a strong domain-notch interaction, the dynamics of polar switching were not found to be inhibited by notches. If anything, notches were found to assist switching. Finite element (FE) modeling suggested that increased switchability arose from localized "hot-spots" in the electric field.

The wires examined in this study were directly machined from commercially obtained single crystal $\mathrm{BaTiO}_{3}$, using a single beam FEI200TEM focused ion beam microscope (FIB). Patterning methodologies employed were similar to those used in previous work. ${ }^{27,28,30}$ Initially, thin lamellae $(\sim 150 \mathrm{~nm}$ in thickness, $\sim 10 \mu \mathrm{m}$ wide, and $\sim 6 \mu \mathrm{m}$ deep $)$ were cut perpendicular to $\langle 100\rangle_{\text {pseudocubic }}$ in the bulk $\mathrm{BaTiO}_{3}$ crystal. Then either the host crystal was tilted in the FIB to allow the ion beam to pattern notched wires directly into the face of the lamella, or the lamella was lifted out of the bulk crystal, placed on a $3 \mathrm{~mm}$ holey carbon-coated copper grid, and returned to the FIB for wire and notch patterning.

Figure 1 shows transmission electron microscopy images of notched wires, and the patterns adopted by the $90^{\circ}$ domains that form on cooling through the Curie temperature. In most cases, either a herringbone pattern was seen [Fig. 1(c)], or simple parallel stripe domains persisted, but the domain periodicity noticeably decreased on moving from the main body of the wire to the notch center [Figs. 1(b)-1(e)]. Both these observations suggest that the notch has had an influence over the manner in which domains have formed.

The observed change in domain periodicity is of particular interest, as prior work, on single crystal $\mathrm{BaTiO}_{3}$ nanoshapes, has consistently seen that the domain periodicity decreases as the ferroelectric becomes smaller, in abeyance of a Landau-Kittel energy expression ${ }^{31-35}$ of the form

$$
G(d, w)=U w+\frac{\gamma d}{w},
$$

suggesting that, under equilibrium conditions, the domain width scales as the square root of size 

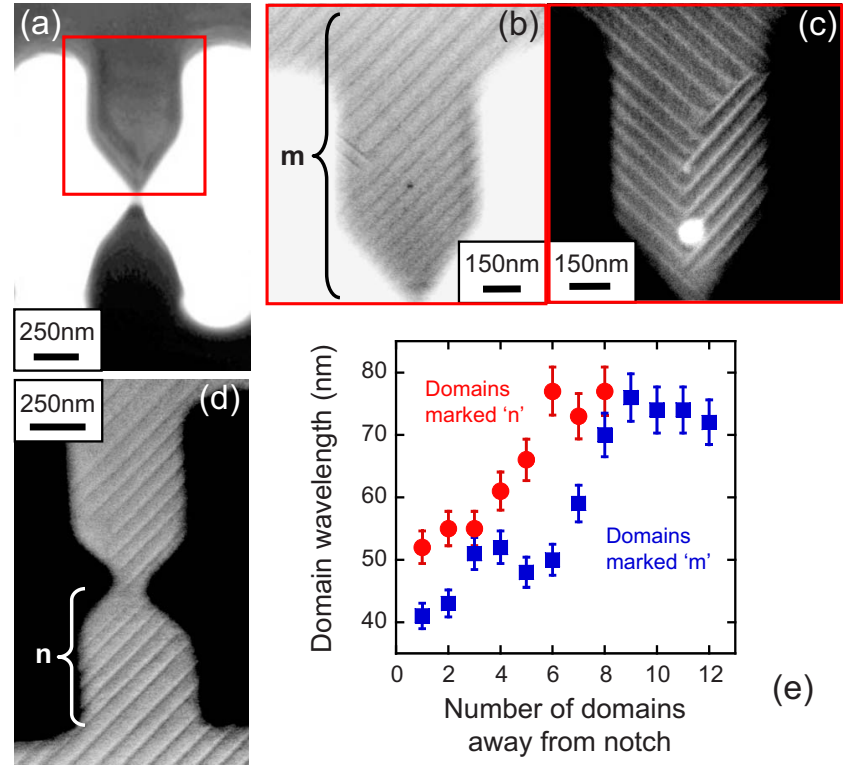

FIG. 1. (Color online) Bright-field (a) and scanning transmission electron microscopy [(b)-(d)] images of the areas surrounding notches in single crystal $\mathrm{BaTiO}_{3}$ wires. The domain patterns formed on cooling through the Curie temperature either showed a marked decrease in the domain wavelength on approaching the core of the notch [(b), (d), and (e)], or "herringbone" patterns reflecting the notch geometry. In both cases there is a clear interaction between the notch and the domain configuration adopted.

$$
\frac{d G(d, w)}{d w}=0 \quad \therefore w=\sqrt{\frac{\gamma d}{U}},
$$

where $G(d, w)$ is the component of free energy which depends on the wavelength of the domain $(w)$ and pertinent dimensions in the ferroelectric object $(d)$; $U$ relates to the energy density of a domain itself, and $\gamma$ is the energy density of the domain wall.

Behavioral adherence of the local domain period to Eqs. (1) and (2) has significant implications for the manner in which the notch should affect domain wall motion. Two pertinent points can be made as follows: first, substituting Eq. (2) into Eq. (1) shows that, at equilibrium, the absolute value of $G(d, w)$ is lower in the notch center (with a relatively small value of $d$ ) than in the thicker region of the wire away from the notch

$$
G(d, w)=U \sqrt{\frac{\gamma d}{U}}+\gamma d \sqrt{\frac{U}{\gamma d}}=2 \sqrt{\gamma U d},
$$

suggesting that, under certain circumstances, domain walls should preferentially be attracted to, and pinned by, the notches; second, when the domain wall density is perturbed away from the zero field equilibrium arrangement, then the

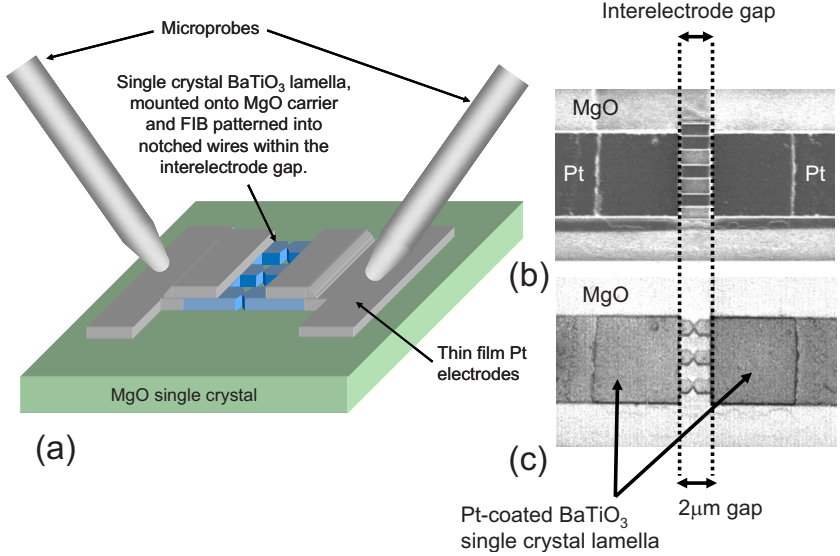

FIG. 2. (Color online) Schematic diagram of the capacitor geometry used to investigate how notches alter the axial switching behavior of ferroelectric nanowires (a). Also shown are plan-view secondary electron images of a $\mathrm{BaTiO}_{3}$ lamella, mounted onto a $\mathrm{MgO}$ carrier, with coplanar platinum electrodes, and an interelectrode gap in which simple wires (b) or wires with notches (c) have been machined.

energy cost for a given local change in domain density $(\delta w)$ is greatest in the notched region, because the curvature of the free energy function around the equilibrium point is greater there than elsewhere on the wire

$$
\frac{\delta^{2} G(d, w)}{\delta w^{2}}=2 \frac{\gamma d}{w^{3}}=2 \frac{U^{3 / 2}}{\sqrt{\gamma d}} \text { at the equilibrium point. }
$$

Both of the above features of the energy landscape should lead to the inhibition of domain wall movement through the notched region, reducing switchability.

To investigate this further, FIB-milled lamellae ( $\sim 300 \mathrm{~nm}$ in thickness) were placed onto functionally passive single crystal $\mathrm{MgO}$ carriers and incorporated into capacitor structures with coplanar Pt electrodes, as had been done in previous work. ${ }^{36,37}$ The $\mathrm{BaTiO}_{3}$ in the interelectrode gap was then FIB-milled to form short sections of wires, $\sim 900 \mathrm{~nm}$ wide by $\sim 2 \mu \mathrm{m}$ long. After thermal annealing, ${ }^{38}$ the switching properties of these short wires were monitored by measuring capacitance-voltage $(\mathrm{C}-\mathrm{V})$ characteristics, taking particular care in the evaluation and subtraction of background capacitance signals. $^{36,37}$ Notches were then FIBmilled into the wires, creating the structures shown both schematically, and in plan-view secondary electron images in Fig. 2. After a further anneal, the switching characteristics were again measured, and compared to those obtained prior to milling the notches. The $\mathrm{C}-\mathrm{V}$ response of the notched and prenotched wires, imaged in Fig. 2, are shown in Fig. 3 at two different temperatures. Since the capacitance at a given
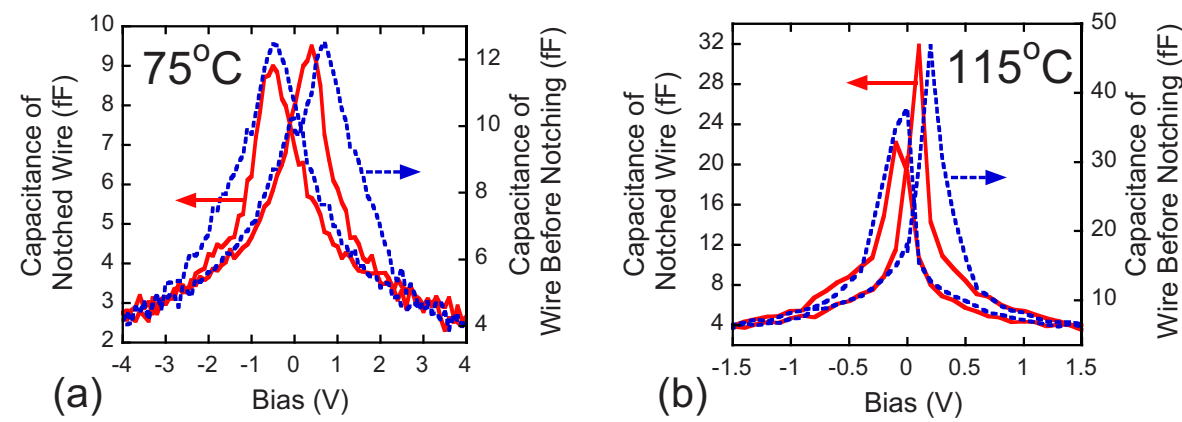

FIG. 3. (Color online) Capacitance as a function of dc bias voltage applied axially along single crystal $\mathrm{BaTiO}_{3}$ wires before and after notches had been cut along their length. As can be seen the peaks in the $\mathrm{C}-\mathrm{V}$ response are sharper after notches have been cut, implying a narrower distribution of voltages across which switching events occur. 


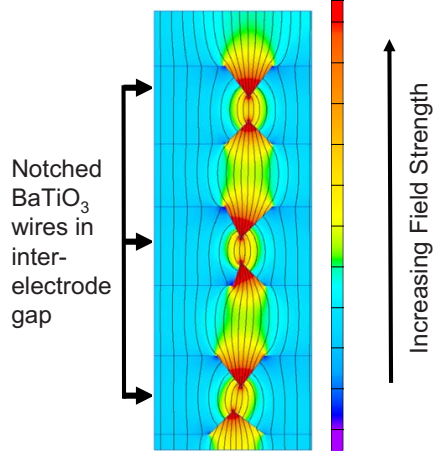

(a)

(b)

FIG. 4. (Color online) FE modeling of the field distribution in the notched wires under applied bias (a) responsible for the switching data presented in Fig. 3. The enhanced field associated with the air gap surrounding the notch has the knock-on effect of causing local field enhancement within the ferroelectric. Antinotches (b) appear to cause local reductions in field strength.

bias voltage is a measure of the alteration in polarization with field at that bias $(C \propto \chi=d P / d E)$, the $\mathrm{C}-\mathrm{V}$ measurement effectively maps the population of local switching events (per unit field) occurring at each value of applied voltage. Even though the overall capacitance signal decreases in the notched sample, it is clear from Fig. 3 that the distribution of voltage, across which switching events occur, is less diffuse in notched wires than in prenotched wires. This is strongly accentuated in Fig. 3(a), but was generally true in all the C-V data sets obtained. Thus, even though imaging of the static domain configurations showed that notches should inhibit the migration of domain walls, electrical switching measurements indicated the opposite.

In an attempt to rationalize this, FE modeling (using "QUICKFIELD") was performed to see how the presence of the notch might alter local electric fields when bias voltage is applied. The outline of the array of three notched wires shown in Fig. 2(c) was traced and used to define the geometry for the modeling. To gain an overall impression of field distribution, $\mathrm{BaTiO}_{3}$ was assigned an isotropic relative permittivity of 1000 (acknowledging the multidomain nature of the ferroelectric during most of the switching cycle). What is immediately evident from Fig. 4(a), is that a great deal of field is dropped across the air-filled regions at the notches. This is expected as large fractions of applied bias are often dropped across areas of low permittivity. More unexpected was the knock-on consequence of field enhancement within the ferroelectric adjacent to the notches. It appears that the effects of field focusing associated with the notch geometry outweigh any pinning interactions between the notch and the domain walls, resulting in the overall increase in switchability observed. An obvious next step is to examine the manner in which antinotches alter axial switching behavior. As can be seen in Fig. 4(b), FE modeling suggests that antinotches are associated with field minima under applied bias.

In summary, an attempt has been made to study the influence that notches have on the static and dynamic behavior of ferroelectric domains. While static domain configurations suggested a notch-domain wall interaction that should inhibit domain wall motion during axial switching, direct functional measurement found switching to be accelerated in the presence of notches. FE modeling suggests that this counterintui- tive observation is related to the unusual field focusing effect that the notch geometry creates.

The authors acknowledge useful discussions with J. F. Scott, G. Catalan, F. D. Morrison, and A. J. Bell.

${ }^{1}$ T. Shinjo, T. Okuno, R. Hassdorf, K. Shigeto, and T. Ono, Science 289. 930 (2000).

${ }^{2}$ A. Wachowiak, J. Wiebe, M. Bode, O. Pietzch, M. Morgenstern, and R. Wiesendanger, Science 298, 577 (2002).

${ }^{3}$ S.-B. Choe, Y. Acremann, A. Scholl, A. Bauer, A. Doran, J. Stohr, and H. A. Padmore, Science 304, 420 (2004).

${ }^{4}$ R. J. Harrison, R. E. Dunin-Borkowski, and A. Putnis, Proc. Natl. Acad. Sci. U.S.A. 99, 16556 (2002).

${ }^{5}$ S. P. Li, D. Peyrade, M. Natali, A. Lebib, Y. Chen, U. Ebels, L. D. Buda, and K. Ounadjela, Phys. Rev. Lett. 86, 1102 (2001).

${ }^{6}$ F. Q. Zhu, G. W. Chern, O. Tchernyshyov, X. C. Zhu, and C. L. Chien, Phys. Rev. Lett. 96, 027205 (2006).

${ }^{7}$ J. Rothman, M. Kläui, L. Lopez-Diaz, C. A. F. Vaz, A. Bleloch, J. A. C. Bland, Z. Cui, and R. Speaks, Phys. Rev. Lett. 86, 1098 (2001).

${ }^{8}$ I. Kornev, H. X. Fu, and L. Bellaiche, Phys. Rev. Lett. 93, 196104 (2004).

${ }^{9}$ I. I. Naumov, L. Bellaiche, and H. X. Fu, Nature (London) 432, 737 (2004).

${ }^{10}$ Z. Wu, N. Huang, J. Wu, W. Duan, and G. L. Gu, Appl. Phys. Lett. 86, 202903 (2005).

${ }^{11}$ J. Wang and T. Zhang, Appl. Phys. Lett. 88, 182904 (2006).

${ }^{12}$ W. Lee, H. Han, A. Lotnyk, M. A. Schubert, S. Senz, M. Alexe, D. Hesse, S. Baik, and U. Gösele, Nat. Nanotechnol. 3, 402 (2008).

${ }^{13}$ A. Gruverman, D. Wu, H.-J. Fan, I. Vrejoiu, M. Alexe, R. J. Harrison, and J. F. Scott, J. Phys.: Condens. Matter 20, 342201 (2008).

${ }^{14}$ B. J. Rodriguez, X. S. Gao, L. F. Liu, W. Lee, I. I. Naumov, A. M. Bratkovsky, D. Hesse, and M. Alexe, Nano Lett. 9, 1127 (2009).

${ }^{15}$ Z. Hu, M. Tian, B. Nysten, and A. Jonas, Nature Mater. 8, 62 (2009).

${ }^{16}$ M. Hayashi, L. Thomas, C. Rettner, R. Moriya, X. Jiang, and S. S. P. Parkin, Phys. Rev. Lett. 97, 207205 (2006).

${ }^{17}$ M. Hayashi, L. Thomas, C. Rettner, R. Moriya, and S. S. P. Parkin, Nat. Phys. 3, 21 (2007).

${ }^{18}$ L. Thomas, M. Hayashi, X. Jiang, R. Moriya, C. Rettner, and S. S. P. Parkin, Nature (London) 443, 197 (2006).

${ }^{19}$ L. Thomas, M. Hayashi, X. Jiang, R. Moriya, C. Rettner, and S. Parkin, Science 315, 1553 (2007).

${ }^{20}$ J. J. Urban, W. S. Yun, Q. Gu, and H. Park, J. Am. Chem. Soc. 124, 1186 (2002).

${ }^{21}$ W. S. Yun, J. J. Urban, Q. Gu, and H. Park, Nano Lett. 2, 447 (2002).

${ }^{22}$ J. E. Spanier, A. M. Kolpak, J. J. Urban, I. Grinberg, L. Ouyang, W. S. Yun, A. M. Rappe, and H. Park, Nano Lett. 6, 735 (2006).

${ }^{23}$ Z. Y. Wang, A. P. Suryavanshi, and M.-F. Yu, Appl. Phys. Lett. 89, 082903 (2006); Z. Y. Wang, J. Hu, and M.-F. Yu, ibid. 89, 263119 (2006)

${ }^{24}$ X. Y. Zhang, X. Zhao, C. W. Lai, J. Wang, X. G. Tang, and J. Y. Dai, Appl. Phys. Lett. 85, 4190 (2004).

${ }^{25}$ Z. H. Zhou, X. S. Gao, J. Wang, K. Fujihara, S. Ramakrishna, and V. Nagarajan, Appl. Phys. Lett. 90, 052902 (2007).

${ }^{26}$ G. Pilania, S. P. Alpay, and R. Ramprasad, Phys. Rev. B 80, 014113 (2009).

${ }^{27}$ A. Schilling, R. M. Bowman, J. M. Gregg, G. Catalan, and J. F. Scott, Appl. Phys. Lett. 89, 212902 (2006).

${ }^{28}$ A. Schilling, R. M. Bowman, G. Catalan, J. F. Scott, and J. M. Gregg, Nano Lett. 7, 3787 (2007).

${ }^{29}$ International Technology Roadmap for Semiconductors (ITRS), $2008 \quad$ Update, http://www.itrs.net/Links/2008ITRS/Update/ 2008Tables_FOCUS_A.xls, spreadsheet title '2008PIDS5' (2008).

${ }^{30}$ A. Schilling, D. Byrne, G. Catalan, K. G. Webber, Y. A. Genenko, G. S. Wu, J. F. Scott, and J. M. Gregg, Nano Lett. 9, 3359 (2009).

${ }^{31}$ L. D. Landau and E. M. Lifshitz, Phys. Z. Sowjetunion 8, 153 (1935).

${ }^{32}$ C. Kittel, Phys. Rev. 70, 965 (1946).

${ }^{33}$ T. Mitsui and J. Furuichi, Phys. Rev. 90, 193 (1953).

${ }^{34}$ A. L. Roitburd, Phys. Status Solidi A 37, 329 (1976).

${ }^{35}$ G. Catalan, J. F. Scott, A. Schilling, and J. M. Gregg, J. Phys.: Condens. Matter 19, 132201 (2007).

${ }^{36}$ L. W. Chang, M. McMillen, and J. M. Gregg, Appl. Phys. Lett. 94, 212905 (2009).

${ }^{37}$ L. W. Chang, M. McMillen, F. D. Morrison, J. F. Scott, and J. M. Gregg, Appl. Phys. Lett. 93, 132904 (2008).

${ }^{38}$ M. M. Saad, R. M. Bowman, and J. M. Gregg, Appl. Phys. Lett. 84, 1159 (2004) 